\title{
Influência da indução artificial de lactação na saúde das vacas
}

Layane Queiroz Magalhães", Danilo de Oliveira, Brenda Matos Fernandes, Amanda Lima Rezende, Paula Batista de Alvarenga, Maria Teresa Nunes Pacheco Rezende, Amanda Bizare, Antônio Vicente Mundim, João Paulo Elsen Saut

Laboratório de Saúde em Grandes Animais, Faculdade de Medicina Veterinária, Universidade Federal de Uberlândia (UFU), Uberlândia, MG, Brasil

*Autor correspondente

e-mail: layanequeirozmagalhaes@gmail.com

\section{Resumo}

A produção brasileira de leite tem crescido devido ao aumento do rebanho, porém, nos últimos anos, o setor tem sofrido com o aumento nos custos de produção e redução de investimentos. Sendo assim, a produção leiteira exige conhecimento técnico e implantação de tecnologias que garantam a produtividade. Protocolos hormonais de indução artificial de lactação constituem alternativa para reduzir perdas econômicas decorrentes de baixos índices reprodutivos, mas pouco se sabe quanto ao efeito destes protocolos na saúde geral dos animais. Objetivou-se avaliar o efeito da indução artificial de lactação na saúde, por meio dos exames físico e complementares. Foram selecionadas 12 vacas mestiças Girolando, adultas, multíparas, saudáveis no exame clínico proposto, não gestantes, com escore de condição corporal (ECC) 2,75 - 3,5 e submetidas ao protocolo de tratamento (21 dias): benzoato de estradiol $30 \mathrm{mg}$ (D0 a D7) e $20 \mathrm{mg}$ (D8 a D14), progesterona $300 \mathrm{mg}$ (D0 a D7), cloprostenol sódico 0,5 mg (D15), dexametasona $40 \mathrm{mg}$ (D18 a D20) e somatotropina bovina recombinante $500 \mathrm{mg}$ (D0, D7, D14 e D21). Procedeu-se, semanalmente, com exame físico (nível de consciência, postura, ECC, mucosas, temperatura retal e frequências cardíaca, respiratória e ruminal) e coletas de sangue para análise do hemograma e bioquímica sérica de proteínas totais, albumina, ureia, creatinina, triglicerídeos, colesterol, AST, GGT, fosfatase alcalina (FA), cálcio, fósforo, magnésio e betahidroxibutirato (BHBA). A lactação ocorreu no $20^{\circ}$ dia de tratamento e caracterizouse pela presença de secreção de leite pela glândula mamária e ordenha produtiva. Não houve alterações no exame físico e não foram observadas alterações no eritrograma, apenas valores próximos ao limite inferior no D21, como provável efeito negativo do corticoide na hematopoese. Neste momento, todos os animais apresentaram leucograma de estresse devido à administração de dexametasona. Foi identificada normoproteinemia, mas houve hiperglobulinemia e hipoalbuminemia durante todo o experimento, estando 
as globulinas estatisticamente mais elevadas no momento D14 e D21 em relação ao D7 (P = 0,0003), momentos de extensas doses de estradiol e dexametasona, respectivamente. Todavia, este perfil proteico tem sido constantemente relatado em animais hígidos das raças Jersey e Girolando de várias idades na região deste experimento. Os valores da AST estiveram elevados nos momentos D7 e D14 pela aplicação de medicação intramuscular. Já FA e GGT apresentaram valores crescentes, não caracterizando hepatopatia pela intensa administração intramuscular de benzoato de estradiol e progesterona. Os animais mantiveram a condição corporal, normocolesterolemia, superiores de triglicerídeos e tendência de redução do BHBA em função da demanda energética para a produção leiteira ao final do protocolo. 0 protocolo foi eficiente ao ser implantado em vacas leiteiras mestiças Girolando e os medicamentos utilizados não interferiram na saúde geral dos animais. 